\title{
Ultrasonographic study of ductus venosus in healthy neonates
}

\author{
Drude Fugelseth, Rolf Lindemann, Knut Liestøl, Torvid Kiserud, Asbjørn Langslet
}

\begin{abstract}
Aim-To assess ultrasonographically the flow pattern and the time of postnatal closure of ductus venosus related to the other fetal shunts.

Methods-Fifty healthy, term neonates were studied from day 1 up to day 18 using a VingMed CFM 800A ultrasound scanner. Results-Ductus arteriosus was closed in 94\% of the infants before day 3 . Ductus venosus, however, was closed in only $12 \%$ at the same time, in $76 \%$ before day 7 , and in all infants before day 18. A closed ductus venosus or ductus arteriosus did not show signs of reopening. Pulsed and colour Doppler flow could be detected across the foramen ovale in all infants during the sequential investigation. At day 1 , when the pulmonary vascular resistance was still high, a reversed Doppler flow velocity signal was seen in ductus venosus in 10 infants $(20 \%)$ and a bidirectional flow in ductus arteriosus in $26(52 \%)$. Closure of the ductus venosus was not significantly correlated with closure of the ductus arteriosus nor related to sex nor weight loss. Conclusions-The time of closure of the ductus venosus evaluated by ultrasonography is much later than that of the ductus arteriosus. The flow pattern in ductus venosus reflects the portocaval pressure gradient and the pressure on the right side of the heart and in the pulmonary arteries. Both the flow pattern in the ductus venosus as well as that in the ductus arteriosus may be an indication of compromised neonatal haemodynamics.

(Arch Dis Child 1997;77:F131-F134)
\end{abstract}

Department of

Paediatrics,

Ullevål University

Hospital,

N-0407 Oslo,

Norway

D Fugelseth

$\mathrm{R}$ Lindemann

A Langlset

Department of Informatics K Liestøl

Department of Obstetrics and

Gynaecology

Haukeland University

Hospital

Bergen

Norway

T Kiserud

Correspondence to: Dr Drude Fugelseth.

Accepted 31 January 1997

Keywords: ductus venosus; ductus arteriosus; foramen ovale; Doppler echocardiography

Animal studies have shown that the ductus venosus during fetal life directs half of the umbilical venous blood directly towards the foramen ovale to maintain preferential streaming to the left atrium. ${ }^{1-3}$ Recent studies have shown that the human ductus venosus operates in a similar way. ${ }^{4}$ The high blood velocity recorded in the ductus venosus is thought to reflect the portocaval pressure gradient and has been suggested as a new method to study compromised fetal haemodynamics. ${ }^{5-9}$ Although the transition of fetal into neonatal circulation has been well described in fetal sheep, ${ }^{1-3}$ less is known about the human ductus venosus. ${ }^{10-13} \mathrm{In}$ a Doppler study Loberant et al described a lower blood velocity in the human ductus venosus postnatally ${ }^{10}$ than had been described prenatally. ${ }^{5}$ In their study most cases had an obliterated ductus venosus within three weeks of birth. More accurate knowledge of the normal flow pattern in the ductus venosus and the forces that influence the flow is desired to evaluate the diagnostic potential of the ductus venosus in postnatal life.

The aim of this study was to assess the flow pattern and time of postnatal closure of ductus venosus related to the other fetal shunts in healthy, term neonates using ultrasonography. An additional objective was to identify changes in Doppler flow that might indicate compromised neonatal haemodynamics.

\section{Methods}

Fifty healthy neonates born at term after uncomplicated pregnancy and vaginal delivery were included in a longitudinal study approved by the Ethics Committee. The birthweights were above the 10th percentile and the Apgar scores were $\geqslant 7$ after 5 minutes. Written informed consent was obtained from the mother/parents.

The infants were examined ultrasonographically with a VingMed CFM 800 scanner (Vingmed Sound, Horten, Norway) using a 5 $\mathrm{MHz}$ sector transducer, colour and pulsed Doppler. Electrocardiographic tracing was recorded simultaneously. All the examinations were performed by one observer (DF). The recordings were stored on colour videotapes, colour, and black and white paper images.

The infants were examined daily from the first to the fourth or fifth day of life. At the first examination, normal anatomy of the heart and the great vessels were confirmed by echocardiography. The infants were further examined on days $7,10,14$ and 18 , until no pulsed or colour

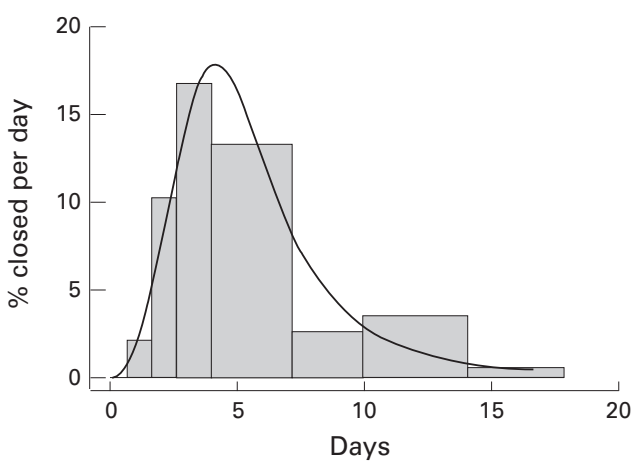

Figure 1 Distribution of closing times for ductus venosus. The height of each bar gives the percentage closure per day during the corresponding time interval. The curve represents the log logistic distribution fitted to the observations. 


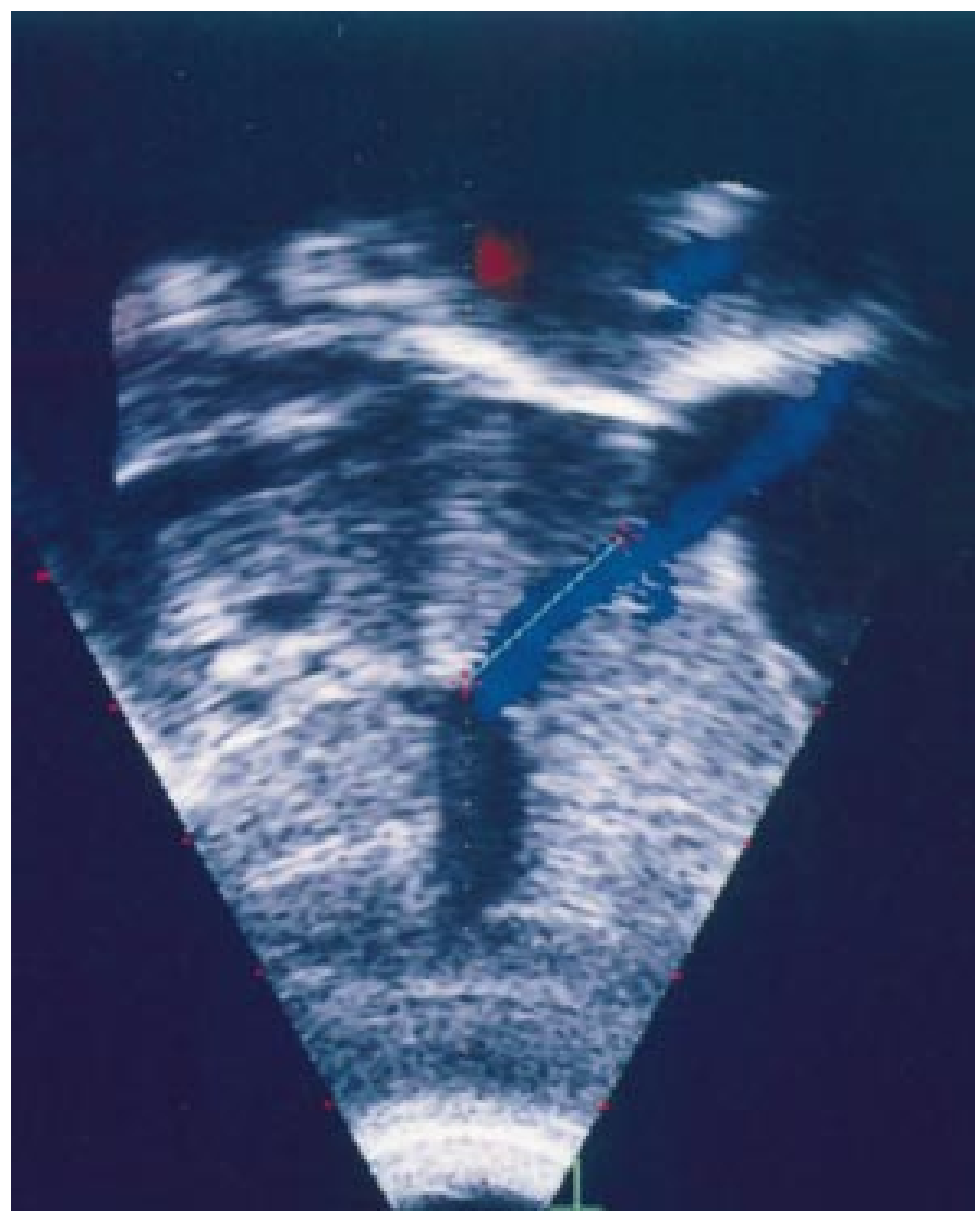

Figure 2 Doppler signals in ductus venosus from the portal sinus to the inferior caval vein at the inlet of the right atrium.

Doppler flow was detected either through ductus arteriosus or ductus venosus. To evaluate the possibility of a closed ductus venosus reopening, 11 infants were re-examined one to seven days after closure. There were no dropouts, but one child was not observed between days 5 and 10 .

Table 1 Demographic data of 50 normal, newborn infants (29 boys, 21 girls) used for study of closure of ductus venosus and ductus arteriosus

\begin{tabular}{lll}
\hline & Mean $(S D)$ & (Range) \\
\hline Gestational age (weeks) & $40(1.05)$ & $(38-42)$ \\
Apgar score (5 min) & $9.1(0.51)$ & $(7-10)$ \\
Birthweight (g) & $3569(381)$ & $(2900-4685)$ \\
Weight loss (g) & $209(107)$ & $(0-540)$ \\
Length (cm) & $50.6(2.09)$ & $(48-57)$ \\
Head circumference (cm) & $35.8(1.35)$ & $(33-39.5)$ \\
\hline
\end{tabular}

Table 2 Number of normal, newborn infants $(n=50)$ with open ductus venosus $D V$ and ductus arteriosus (DA) at different time intervals after birth

\begin{tabular}{|c|c|c|c|c|c|c|}
\hline \multirow[b]{2}{*}{ Day } & \multicolumn{3}{|l|}{$D V$} & \multicolumn{3}{|l|}{$D A$} \\
\hline & $\begin{array}{l}\text { Hours mean } \\
(S D)\end{array}$ & $\begin{array}{l}\text { No with open } \\
\text { duct }\end{array}$ & $(\%)$ & $\begin{array}{l}\text { Hours mean } \\
(S D)\end{array}$ & $\begin{array}{l}\text { No with open } \\
\text { duct }\end{array}$ & $(\%)$ \\
\hline 1 & $14.4(6.2)$ & 50 & $(100)$ & $14.4(6.2)$ & 41 & $(82)$ \\
\hline 2 & $38.0(7.1)$ & 49 & $(98)$ & $36.4(6.7)$ & 14 & (28) \\
\hline 3 & $61.7(7.1)$ & 44 & (88) & $57.8(6.1)$ & 3 & (6) \\
\hline $4-5$ & $93.2(8.6)$ & 33 & (66) & $96.3(11.0)$ & 1 & (2) \\
\hline 7 & $171.3(11.4)$ & 12 & (24) & 168 & 0 & \\
\hline 10 & $237.6(14.1)$ & 8 & (16) & & & \\
\hline 14 & $337.4(4.9)$ & 1 & (2) & & & \\
\hline 18 & 429 & 0 & & & & \\
\hline
\end{tabular}

The ductus venosus was visualised both from a mid-subcostal, near sagittal plane, and from a more right-sided subhepatic, near sagittal view. Identification of the ductus venosus was accepted when the continuous luminal connection between the portal sinus and the inferior caval vein was shown. Measurements of the width of the isthmic portion and the mid-portion as well as the length of the ductus venosus were performed from a mid-subcostal insonation. The Doppler velocimetry was done from a right subhepatic view to obtain as favourable insonation angle as possible. At least three measurements of the peak velocities both at the inlet, midportion, and outlet of the vessel were performed at each session, and the mean value was used in further calculations.

The ductus arteriosus was investigated both from subcostal and parasternal short axis views. The minimal ductus arteriosus orifice diameter was measured. The Doppler velocimetry of the ductus arteriosus was carried out according to Musewe et al. ${ }^{14}$

The foramen ovale and the atrial shunting were visualised by subcostal insonation.

Regression analysis was used to assess the influence of background variables on closing of the shunts, and analysis of variance was used when comparing velocity measurements at different days. When testing coherence of reversed/bidirectional flow in ductus venosus and ductus arteriosus, Fisher's exact test was used. Test results with a $\mathrm{P}$ value of $<0.05$ were regarded as significant. To obtain a smooth estimate of the distribution of closing times for ductus venosus (fig 1), we used a log logistic curve. The parameters of this curve were found by standard maximum likelihood estimation, using the exact hours of the last observations before closing and the first observations after closing.

\section{Results}

The descriptive data for the study population are presented in table 1 . The open ductus venosus, foramen ovale, and ductus arteriosus were easily detected by two dimensional and colour and pulsed Doppler in all infants.

The results on the closing of ductus venosus are shown in table 2 and fig 1 . While only $12 \%$ were closed by day 3, most were closed during the latter part of the first week, and all were closed by day 18. A closed ductus venosus or ductus arteriosus did not show signs of reopening (11 cases examined).

The length of the ductus venosus was measured to a mean (SD) 15.3 (1.0) mm. The width at the inlet of the vessel was measured the first day to $1.35(0.4) \mathrm{mm}$ and at the midpoint of the vessel to $1.96(0.49) \mathrm{mm}$.

Colour and pulsed Doppler signals in the ductus venosus showed a cephalic biphasic waveform directed from the portal sinus to the inferior caval vein (fig 2). The typical low Doppler velocity signal peaked during ventricular systole and diastole and reached a nadir during atrial systole (figs 3 and 4). The Doppler flow pattern varied according to respiration, with the highest flow velocity signal at the inspiration phase. The mean maximum velocity signal 


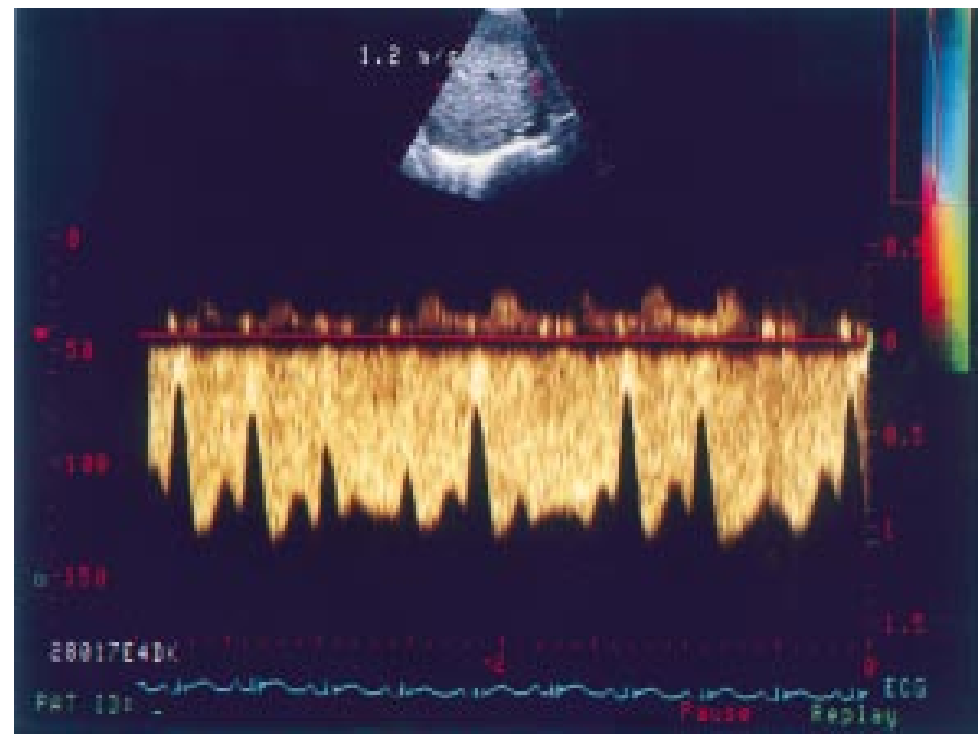

Figure 3 Cephalic biphasic waveform signals in the ductus venosus. The low velocity pattern shows a peak during ventricular systole and diastole, and a nadir during atrial systole.

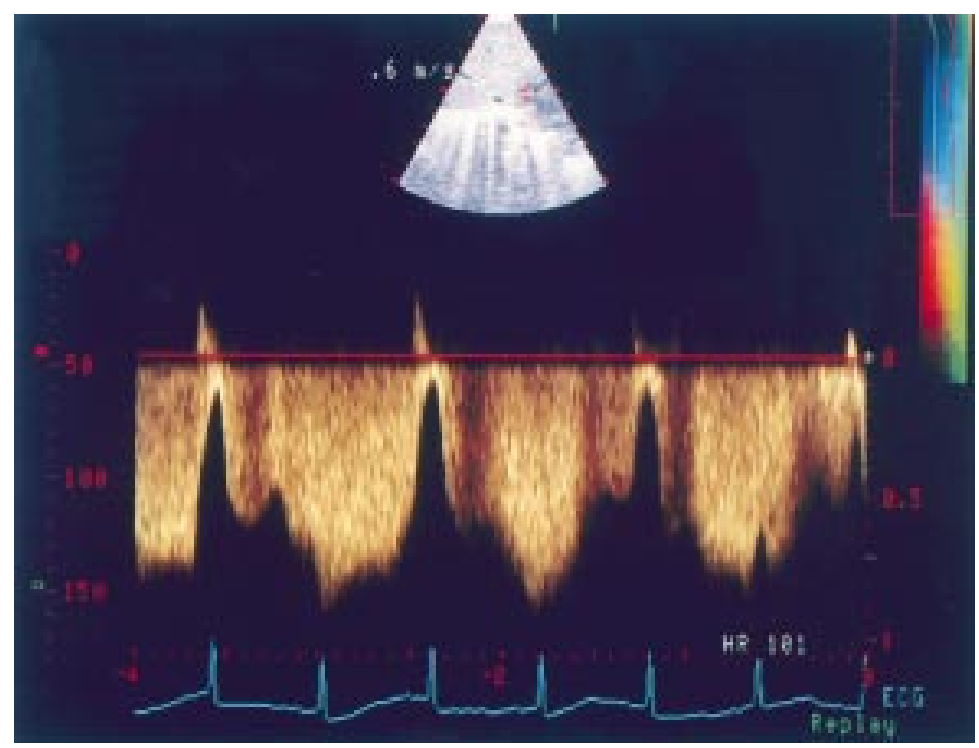

Figure 4 During the first day of life, a short reversed velocity flow signal during atrial systole in ductus venosus was observed in 10 infants.

varied between $0.47(0.11)$ milliseconds at day 1 and $0.55(0.12)$ milliseconds at day 7 (no significant difference). The mean maximum velocity at the last measurement before closure was 0.49 milliseconds, close to the average of the other recordings. There were no significant differences between the velocities measured at the inlet, midportion and outlet of the vessel.

During the first day of life a short, reversed Doppler flow pattern during atrial systole in ductus venosus could be observed in 10 infants (fig 4). The respiratory rate is slower than the heart rate. The flow velocity signals in ductus venosus are influenced by the respiration, with a retrograde flow during alternate cardiac cycles.

The distribution of closing times for ductus arteriosus is shown in table 2. The Doppler flow velocity signals showed bidirectional shunting in 26 of the infants at the first examination. The duration of right to left shunting was less than $60 \%$ of the cardiac cycles. From day 2 the shunting was mainly left to right.

Of the 10 infants with a reversed flow in the ductus venosus at day 1 , one had a closed ductus arteriosus. In the other nine infants a bidirectional shunt across the ductus arteriosus was found, compared with only 17 of 40 infants without reversed flow in ductus venosus $(\mathrm{P}<0.05)$.

The foramen ovale was open in all infants during the sequential investigations both with two dimensional imaging and colour Doppler ultrasonography. The opening varied from a separation of the septum primum and secundum of 2-3 $\mathrm{mm}$ throughout the whole cardiac cycles, to a separation barely recognisable during systole and early diastole. The direction of the atrial shunt flow was predominantly left to right, but with a small right to left shunt in diastole and especially in atrial systole during the first days of life. Over time, the opening gradually diminished in all infants.

We found no significant correlation between the time of closure of ductus venosus and ductus arteriosus. Furthermore, the time of closure of ductus venosus was not significantly related to sex, birthweight, or weight loss within the group of term neonates studied.

\section{Discussion}

The transition from fetal to postnatal human circulation has been well studied with Doppler echocardiography in terms of the ductus arteriosus, foramen ovale, and pulmonary vascular resistance. ${ }^{15-21}$ Loberant et al studied the flow pattern and closure of ductus venosus in human neonates using ultrasound techniques. ${ }^{10}$ This study covers the same time period as our study (up to 18 days), but with longer time intervals between examinations and with 20 $60 \%$ dropouts at different ages. ${ }^{10}$ Both the Doppler flow velocity pattern and the time of closure in our study differs in some respect from what was found in that study. Loberant et al found a constant venous waveform with low velocity signals, ${ }^{10}$ while we found a pattern that varied according to the cardiac cycle and the respiration, and a reversed Doppler flow signal in 10 infants at the first examination. We found an open ductus venosus in $24 \%$ on day 7 and in none of the infants on day 18 . Loberant et al found patency in $68 \%$ at 6-7 days after birth and in $11 \%$ on day $17-18 .^{10}$

There are several reasons why our results might have differed from the findings of Loberant et al. ${ }^{10}$ Although the Doppler signals in the ductus venosus differ from the signals in the hepatic veins, which have a more constant and low velocity waveform, the separation may be difficult. In this respect, we believe that close time intervals between examinations, only one observer, and different technology were advantageous in our study.

The time of closure and the Doppler flow pattern of the ductus arteriosus are much the same as other authors have described. ${ }^{15-17}$

The lack of correlation between time of closure of ductus venosus and ductus arteriosus 
may indicate different mechanism for closing of those shunts.

The Doppler flow across the foramen ovale showed a decrease over the observation period of each infant. The two dimensional image of a separation of the septum primum and secundum was found during all our investigations. We can conclude that the foramen ovale closes later than both the ductus venosus and ductus arteriosus, but we have not followed up the infants until the foramen ovale is closed. Our results differ from what other authors have observed: Hiraishi et al found a shunt signal in only $47 \%$ on the fourth day of life. ${ }^{18}$

Several methods for estimating pulmonary artery pressure with Doppler echocardiography are currently available. The pulmonary artery systolic pressure estimation from the peak velocity of the tricuspid regurgitation jet is judged to be the most accurate non-invasive method. ${ }^{22-24}$ Bidirectional ductal shunting can also be used as an indirect reflection of the pulmonary vascular pressure. ${ }^{14}$ The maximal tricuspidal regurgitation signal can be difficult to detect. The ductus arteriosus, as shown both in ours and other studies, ${ }^{15-17}$ closes early. However, our results shows that the ductus venosus remains open for much longer than the ductus arteriosus. The Doppler flow velocity signals in ductus venosus, with a reversed signal during atrial systole at the time of bidirectional shunting in ductus arteriosus, reflect the pressure in the right side of the heart and the pulmonary arteries. The duration of right to left shunting was less than $60 \%$ of the cardiac cycles, indicating a high pulmonary artery pressure but less than the systemic arterial pressure. ${ }^{11}$

Ductus venosus velocimetry may represent a possible method of evaluating compromised neonatal haemodynamics.

We thank Vingmed Sound, Norway, for providing the ultrasound equipment used in this study.

1 Behrman RE, Lees MH, Peterson EN, de Lannoy CW, Seeds AE. Distribution of the circulation in the normal and asphyxiated fetal primate. Am F Obstet Gynecol 1970; 108: 956-69.

2 Edelstone DJ, Rudolph AM. Preferential streaming of ductus venosus blood to the brain and heart in fetal lambs. Am 7 Physiol 1979;237:724-9.

3 Rudolph AM. Distribution and regulation of blood flow in the fetal and neonatal lamb. Circ Res 1985;57:811-21.

4 Kiserud T, Eik-Nes SH, Blaas H-G, Hellevik LR. Foramen ovale: an ultrasonographic study of its relation to the infe- rior vena cava, ductus venosus and hepatic veins. Ultrasound Obstet Gynecol 1992;2:389-96.

5 Kiserud T, Eik-Nes SH, Blaas H-G, Hellevik LR. Ultrasonographic velocimetry of the fetal ductus venosus. Lancet 1991;338:1412-4.

6 Kiserud T, Eik-Nes SH, Hellevik LR, Blaas H-G. Ductus venosus blood velocity changes in fetal cardiac diseases. $\mathcal{F}$ Matern Fetal Invest 1993;3:15-20.

7 Kiserud T, Eik-Nes SH, Blaas H-G, Hellevik LR, Simensen B. Ductus venosus blood velocity and the umbilical circulation in the seriously growth-retarded fetus. Ultrasound Obstet Gynecol 1994;4:109-14

8 Hecher K, Snijders R, Campbell S, Nicolaides K. Fetal venous, intracardiac, and arterial blood flow measurements in intrauterine growth retardation: relationship with fetal blood gases. Am $\mathcal{F}$ Obstet Gynecol 1995;173:10-5.

9 Oepkes D, Vandenbussche FP, van Bel F, Kanhai HHH. Fetal ductus venosus blood velocities before and after transfusion in red-cell alloimmunized pregnancies. Obstet Gynecol 1993; 82: 237-41.

10 Loberant N, Barak M, Gaitini D, Herskovits M, Ben-Elisha M, Roguin N. Closure of the ductus venosus in neonates: Finding on real-time gray-scale, color-flow Doppler, and duplex-Doppler sono-graphy. Am f Roentgenol 1992;159: 1083-5.

11 Lind J. Human fetal and neonatal circulation. Int $\mathcal{f}$ Cardiol 1977;5:265-81.

12 Peltonen T, Hirvonen L. Experimental studies on fetal and neonatal circulation. Acta Paediatr Scand 1965;44:1-55.

13 Hirvonen L, Peltonen T, Ruokola M. Angiography of the newborn with contrast injected into the umbilical vein. Ann Paediatr Fenn 1961; 7:124-6.

14 Musewe NN, Poppe D, Smallhorn JF, Hellman J, Whyte H, Smith B, et al. Doppler echocardiographic measurement of pulmonary artery pressure from ductal Doppler velocities in the newborn. $\mathcal{F}$ Am Coll Cardiol 1990;15:446-56.

15 Alenick DS, Holzman IR, Ritter SB. The neonatal transitional circulation: A combined noninvasive assessment. Echocardiography 1993;9:29-36.

16 Hiraishi S, Misawa H, Oguchi K, Kadoi N, Saito K, Fujino $\mathrm{N}$, et al. Two-dimensional Doppler echocardiographic $\mathrm{N}$, et al. Two-dimensional Doppler echocardiographic newborn infants. F Pediatr 1987;111:755-60.

17 Gentile R, Stevenson G, Dooley T, Franklin D, Kawabori I, Pearlman A. Pulsed Doppler echocardiographic determination of time of ductal closure in normal newborn infants. F Pediatr 1981;98:443-8.

18 Hiraishi S, Agata Y, Saito K, Oguchi K, Misawa H, Fujino $\mathrm{N}$, et al. Interatrial shunt flow profiles in newborn infants: a color flow and pulsed Doppler echocardiographic study. Br Heart f 1991;65:41-5.

19 Evans NJ, Archer LNJ. Postnatal circulatory adaptation in healthy term and preterm neonates. Arch Dis Child 1990;65:24-6.

20 Walther FJ, Benders MJ, Leighton JO. Early changes in the neonatal circulatory transition. F Pediatr 1993;123:625-32.

21 Agata Y, Hiraishi S, Misawa H, Hirota H, Nowatari M, Hiura K, et al. Regional blood flow distribution and left ventricular output during early neonatal life: A quantitative ultrasonographic assessment. Pediatr Res 1994;36:80510.

22 Currie PJ, Seward JB, Chan K-L, Fyfe DA, Hagler DJ, Mair DD, et al. Continuous wave Doppler determination of right ventricular pressure: A simultaneous Dopplerright ventricular pressure: A simultaneous Doppler-
catheterization study in 127 patients. $7 \mathrm{Am}$ Coll Cardiol catheterization

23 Chan KL, Currie PJ, Seward JB, Hagler DJ, Mair DD, Tajik AJ. Comparision of three Doppler ultrasound methods in the prediction of pulmonary artery pressure. $7 \mathrm{Am}$ Coll Cardiol 1987;9:549-54.

24 Berger M, Haimowitz A, van Tosh A, Berdoff RL, Goldberg E. Quantitative assessment of pulmonary hypertension in patients with tricuspid regurgitation using continuous wave Doppler ultrasound. $\mathcal{F}$ Am Coll Cardiol 1985; 6:35965 . 